\title{
Analiza jakości interfejsu aplikacji internetowej z wykorzystaniem eye-trackingu - studium przypadku
}

\author{
Marcin Jusiak*, Marek Miłosz \\ Politechnika Lubelska, Instytut Informatyki, Nadbystrzycka 36B, 20-618 Lublin, Polska
}

Streszczenie. Artykuł przedstawia przykład wykorzystania technologii eye-trackingu w badaniu jakości interfejsu aplikacji internetowej. Przedmiotem badań była część webowa systemu FastCat, wspomagającego obsługę miejskich wyścigów rowerowych. Wykorzystana metodyka badawcza polegała na realizacji eksperymentu z użytkownikami, w trakcie którego wykonywane były opracowane typowe scenariusze wykorzystania systemu. Działania użytkowników były rejestrowane z użyciem technologii eye-trackingu i zostały poddane szczegółowej analizie. Sześcioosobowa grupa badawcza posiadała profil analogiczny do potencjalnych użytkowników aplikacji. W końcowej części artykuły przedstawiono rezultaty badań ilościowych, wykaz wykrytych błędów w interfejsie, a także wnioski ukierunkowane na poprawę jego jakości.

Słowa kluczowe: eye-tracking; aplikacja; jakość interfejsu

*Autor do korespondencji.

Adres e-mail: marcin.jusiak@ pollub.edu.pl

\section{Analysis of the quality of web application interface using eye-tracking - a case study}

\author{
Marcin Jusiak*, Marek Miłosz \\ Institute of Computer Science, Lublin University of Technology, Nadbystrzycka 36B, 20-618 Lublin, Poland
}

\begin{abstract}
The article presents an example of the use of eye-tracking technology in examining the quality of the web application interface. The subject of the research was the web part of the FastCat system, supporting the service of urban cycling races. The research methodology based on the implementation of an active experiment with users, using typical scenarios of system developed. User activities were recorded using eyetracking technology and were subjected to detailed analysis. The six-person research group had a profile analogous to potential users of the application. The final part of the article presents the results of quantitative research, a list of detected errors in the interface, as well as conclusions aimed at improving its quality.
\end{abstract}

Keywords: eye-tracking; application; interface quality

*Corresponding author.

E-mail addresses: marcin.jusiak@ pollub.edu.pl

\section{Wstęp}

W dzisiejszych czasach ciężko wyobrazić sobie brak możliwości korzystania z dostępu do Internetu. Szybko rosnąca popularność sieci komputerowych spowodowała możliwość ich wykorzystywania w wielu dziedzinach życia. Rozwój technologiczny, spowodowany coraz częstszym stosowaniem różnorodnych urządzeń, takich jak smartfony czy laptopy, wymusza na programistach aplikacji webowych tworzenie interfejsów responsywnych, czyli dostosowanych do różnych rozdzielczości ekranu w zależności od urządzenia $[1,2]$. Główny nacisk położony jest na prostotę, przejrzystość aplikacji i ogólnie pojętą użyteczność $[1,3]$. W celu sprawdzenia poprawności utworzonego interfejsu zostało opracowanych bardzo wiele metod badawczych. Metody te można podzielić wg różnych kryteriów na [4]:

automatyczne i manualne,

z udziałem użytkownika i bez takowego.

W trakcie badań jakości eksperymentu używane są różnego rodzaju techniki, takie jak [4]: testowanie, inspekcja, wywiad, modelowania analityczne czy też symulacja.
Jedną z najbardziej efektywnych metod analizy jakości interfejsu aplikacji jest eksperyment badawczy z udziałem użytkowników, realizowany metodą testowania $\mathrm{z}$ wykorzystaniem scenariuszy. $\mathrm{W}$ tej metodzie już grupa badawcza składająca się z 6 . użytkowników jest w stanie wykryć większość problemów z interfejsem [3]. W metodzie tej, do rejestracji działań użytkowników coraz częściej używana jest technologia eye-trackingu $[5,6]$.

W niniejszym artykule zaprezentowano przypadek wykorzystania metody eksperymentu $\mathrm{z}$ użytkownikiem do badania jakości interfejsu autorskiej aplikacji webowej, będącej częścią systemu FastCat, wspomagającego obsługę miejskich wyścigów rowerowych. Przedstawiono metodę, rezultaty oraz omówiono szczegółowo wyniki zrealizowanego eksperymentu.

\section{Opis obiektu badań}

Badana aplikacja jest częścią systemu FastCat wspomagającego obsługę miejskich wyścigów rowerowych [7]. System składa się z aplikacji mobilnej dostępnej na 
platformę Android oraz z aplikacji webowej. Badania zostały przeprowadzone na interfejsie aplikacji webowej.

Do podstawowych funkcji, realizowanych przez webową część systemu FastCat należą:

- tworzenie, komentowanie i usuwanie postów,

- zapisywanie się na wyścig,

- organizacja nowego wyścigu,

- dodawanie punktu kontrolnego do wyścigu.

Pozostałe elementu funkcjonalności realizuje interfejs aplikacji mobilnej. System FastCat powstał w ramach dyplomowej pracy inżynierskiej [7].

\section{Eye-tracking jako metoda badawcza}

Okulografia (ang. eye-tracking) jest to technologia pozyskiwania danych o postrzeganiu człowieka, wykorzystująca technikę śledzenia ruchów gałki ocznej, punktów skupienia wzroku oraz rozmiaru źrenicy osoby poddanej badaniu. Technologia ta jest stosowana od ponad 100 lat $\mathrm{w}$ wielu dziedzinach, między innymi w psychologii, ergonomii, marketingu i interakcji człowieka $\mathrm{z}$ komputerem. Obecnie, eye-tracking wykorzystuje bezkontaktowe, bezpieczne i bezinwazyjne śledzenie ruchów gałki ocznej przy pomocy promieni podczerwonych [5]. Wykorzystywane są specjalne urządzenia - eye-trackery stacjonarne (rys. 1) i mobilne - oraz specjalistyczne oprogramowanie do rejestracji danych, ich przetwarzania i wizualizacji wyników.

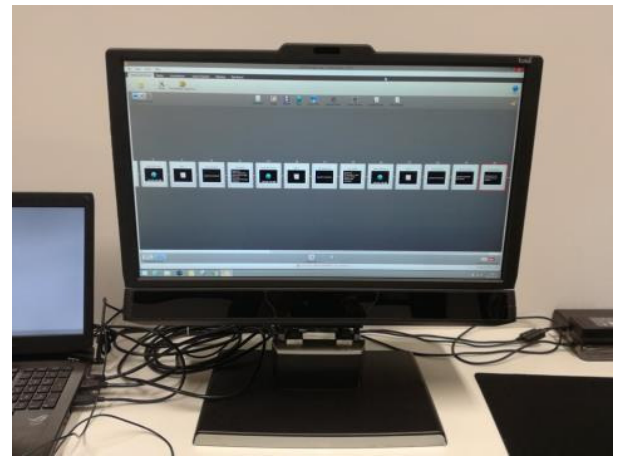

Rys. 1. Eye-tracker Tobii TX300

\section{Metodyka realizacji badań}

Badania zostały wykonane zgodnie $\mathrm{z}$ metodyką zaprezentowaną w pracy [8]. Składa się na nią następujące etapy [8]:

- Opracowanie scenariuszy wykorzystania aplikacji i przeprowadzenia eksperymentu.

- Organizacja stanowiska badawczego.

- Dobór grupy badawczej.

- Przeprowadzenie eksperymentu i zbieranie danych.

- Obróbka rezultatów eksperymentu i ich wizualizacja.

- Analiza, dyskusja i wysnucie wniosków.

\subsection{Scenariusze badawcze}

W trakcie przygotowywania badań opracowane zostały następujące scenariusze (zadania do realizacji przez badanych użytkowników) wykorzystania aplikacji webowej systemu FastCat [7]:

1) Jako zalogowany użytkownik utwórz nowy post.

2) Zapisz się wyścig o nazwie: „Lublin sierpień 2018”.

3) Jako zalogowany użytkownik zorganizuj nowy wyścig o nazwie „Ulicami Lublina 2018”.

4) W wyścigu „Lublin sierpień 2018” dodaj dowolny punkt kontrolny.

5) Jako zalogowany użytkownik usuń utworzony przez Ciebie post.

Opracowany został także scenariusz badań, tj. odpowiedni tekst dla uczestników, prowadzący ich ,za rękę” w trakcie realizacji eksperymentu. W ten sposób osoba nadzorująca eksperyment nie ingeruje w kolejność i sposób jego przeprowadzenia. Ma to zapewnić realizację eksperymentu w takich samych warunkach dla wszystkich uczestników.

\subsection{Organizacja stanowiska badawczego}

Eksperyment został przeprowadzony listopadzie 2018 r. przy wykorzystaniu eye-trackera Tobii TX300 (rys. 1) wraz z oprogramowaniem Tobii Studio Pro w Laboratorium Analizy Ruchu i Ergonomii Interfejsów (LARiEI) Instytutu Informatyki Politechniki Lubelskiej.

$\mathrm{Na}$ wykorzystane w badaniach stanowisko testowe składały się następujące elementy:

- Eye tracker: Tobii TX300 (Tobii AB, Sweden).

- Oprogramowanie eye-trackera: Tobii Pro Studio (wersja 3.3.2) Enterprise edition.

- Monitor TFT 23" zintegrowany z eye-trackerem,

- Urządzenie do obrazowania: Tobii User Camera v3.

- Laptop (Asus G750JX-T4191H, Procesor Intel Core i74700HQ, Pamięć RAM 8 GB, system Operacyjny: Windows 8.1).

- Nagrywanie dźwięku: Microphone (Realtek High Definition) - zintegrowana z płytą główną.

- Przeglądarka internetowa: Internet Explorer 11(wersja 11.0.37).

Oprogramowanie eye-trackera korzysta ze starszej wersji przeglądarki internetowej Internet Explorer, bez możliwości zmiany. W związku z tym, w celu poprawnego działania aplikacji webowej, należało poprawić niektóre moduły aplikacji, które w przeciwnym wypadku uniemożliwiałyby wykonanie zadań przez uczestników eksperymentu.

\subsection{Grupa badawcza}

System FastCat [7] przeznaczony jest dla młodych, aktywnych osób. Osoby te zwykle dobrze są zaznajomione z technologiami webowymi mobilnymi jako użytkownicy. Elementy te wpłynęły na dobór grupy badawczej. 
W badaniu wzięło udział 6 osób w wieku 23-24 lat: 4. kobiety oraz 2. mężczyzn. Wszyscy byli studentkami i studentami Politechniki Lubelskiej.

\subsection{Eksperyment, zbieranie danych i ich wizualizacja}

Badania zrealizowano $\mathrm{w}$ pomieszczeniu laboratoryjnym LARiEI, które przypomina pomieszczenie biurowe. Poszczególni użytkownicy po krótkim przeszkoleniu realizowali samodzielnie scenariusz badań, korzystając z wydrukowanego scenariusza. Dane były rejestrowane przy pomocy stanowiska badawczego (rozdz. 4.2).

Zarejestrowane w trakcie eksperymentów dane posłużyły do późniejszej analizy, która określiła:

- Parametry ilościowe wykonania poszczególnych zadań (czas realizacji zadania, liczba fiksacji na poszczególnych fragmentach strony, liczba popełnionych błędów).

- Problemy użyteczności, wykryte przez poszczególnych użytkowników.

Pozyskane dane posłużyły także do stworzenia map cieplnych punktów fiksacji wzroku na poszczególnych podstronach serwisu, które pełnią wspomagającą role w trakcie analizy problemu jakości interfejsu.

\section{Rezultaty badań}

W tabeli 1 przedstawiono czasy realizacji poszczególnych zadań przez użytkowników i wyniki ich podstawowej analizy statystycznej.

Tabela 1. Czasy wykonywania zadań przez użytkowników

\begin{tabular}{|c|c|c|c|c|c|c|}
\cline { 2 - 7 } \multicolumn{1}{c|}{} & \multicolumn{7}{c|}{ Czas [s] } \\
\hline $\begin{array}{l}\text { Zadanie/ } \\
\text { Użytkownik }\end{array}$ & 1 & 2 & 3 & 4 & 5 & Suma \\
\hline 1 & 77 & 10 & 29 & 30 & 20 & 166 \\
\hline 2 & 857 & 44 & 313 & 171 & 45 & 1430 \\
\hline 3 & 206 & 16 & 111 & 76 & 93 & 502 \\
\hline 4 & 426 & 16 & 233 & 126 & 38 & 839 \\
\hline 5 & 60 & 14 & 52 & 22 & 33 & 181 \\
\hline 6 & 102 & 29 & 48 & 25 & 17 & 221 \\
\hline Srednia & 288 & 21.5 & 131 & 75 & 41 & 556.5 \\
\hline Minimum & 60 & 10 & 29 & 22 & 17 & 166 \\
\hline Maksimum & 857 & 44 & 313 & 171 & 93 & 1430 \\
\hline
\end{tabular}

Tabela 2 zawiera dane o liczbie fiksacji wzroku użytkowników w trakcie realizacji badań. Ekran został poddany segmentacji na trzy podstawowe części: oba menu (lewe i prawe górne) i pozostałą część ekranu.

W wyniku analizy zapisów z badań określono liczbę popełnionych błędów $\mathrm{w}$ trakcie realizacji zadań przez poszczególnych użytkowników oraz ich typy. Rezultaty przedstawiono w tabelach 3 i 4.
Tabela 2. Liczba fiksacji wzroku poszczególnych użytkownikach na trzech segmentach ekranu

\begin{tabular}{|c|c|c|c|}
\cline { 2 - 4 } \multicolumn{1}{c|}{} & \multicolumn{3}{c|}{ Liczba fiksacji } \\
\hline Użytkownik & $\begin{array}{c}\text { Lewe górne } \\
\text { menu }\end{array}$ & $\begin{array}{c}\text { Pozostała } \\
\text { część strony }\end{array}$ & $\begin{array}{c}\text { Prawe górne } \\
\text { menu }\end{array}$ \\
\hline 1 & 5 & 20 & 0 \\
\hline 2 & 30 & 84 & 13 \\
\hline 3 & 3 & 31 & 2 \\
\hline 4 & 24 & 70 & 1 \\
\hline 5 & 24 & 36 & 3 \\
\hline 6 & 8 & 23 & 0 \\
\hline Srednia & 15,67 & 44 & 3,17 \\
\hline Suma & 94 & 264 & 19 \\
\hline
\end{tabular}

Tabela 3. Liczba zarejestrowanych błędów popełnionych przez użutkowników

\begin{tabular}{|c|c|c|c|c|c|c|}
\hline $\begin{array}{l}\text { Zadanie/ } \\
\text { Użytkownik }\end{array}$ & 1 & 2 & 3 & 4 & 5 & Suma \\
\hline 1 & 8 & 0 & 0 & 0 & 3 & 11 \\
\hline 2 & 14 & 0 & 6 & 0 & 1 & 21 \\
\hline 3 & 9 & 0 & 1 & 0 & 9 & 19 \\
\hline 4 & 17 & 0 & 6 & 1 & 3 & 27 \\
\hline 5 & 3 & 0 & 2 & 0 & 1 & 6 \\
\hline 6 & 5 & 0 & 2 & 0 & 1 & 8 \\
\hline Suma & 56 & 0 & 17 & 1 & 18 & 82 \\
\hline
\end{tabular}

Tabela 4. Wykryte problemy użyteczności stron

\begin{tabular}{|c|c|c|c|c|c|}
\hline $\begin{array}{l}\text { Zadanie/ } \\
\text { Użytkownik }\end{array}$ & 1 & 2 & 3 & 4 & 5 \\
\hline 1 & $\mathrm{Y}$ & & & & \\
\hline 2 & $\mathrm{X}, \mathrm{Y}, \mathrm{Z}$ & & $\mathrm{X}$ & & $\mathrm{X}$ \\
\hline 3 & $\mathrm{X}, \mathrm{Y}$ & & & & $\mathrm{X}, \mathrm{Y}$ \\
\hline 4 & $\mathrm{X}, \mathrm{Y}$ & & $\mathrm{X}$ & & $\mathrm{X}$ \\
\hline 5 & & & & & $\mathrm{X}$ \\
\hline 6 & $\mathrm{X}, \mathrm{Y}$ & & & & \\
\hline
\end{tabular}

Legenda: $\mathrm{X}$ - problem ze znalezieniem danej funkcjonalności., Y problem podczas wypełniania pól formularza, $\mathrm{Z}$ - użycie złej funkcjonalności.

Mapy cieplne, stworzone na podstawie pozyskanych danych przedstawione zostały na rysunkach 2-4.

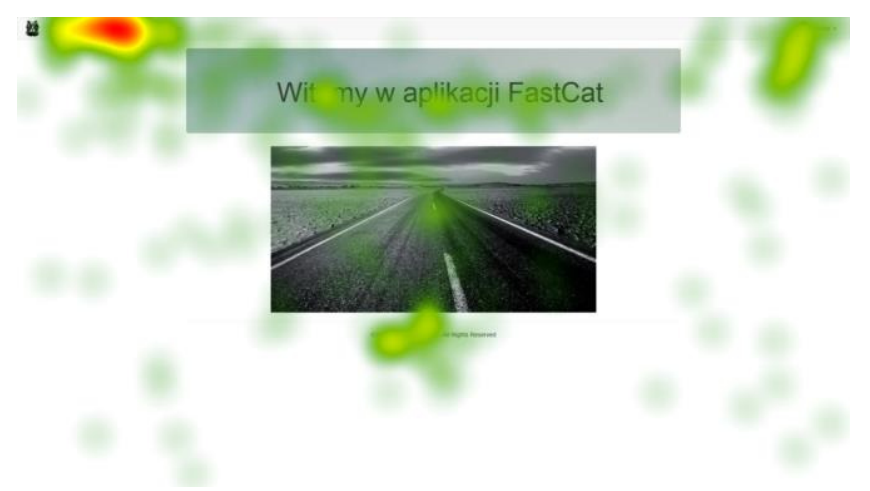

Rys. 2. Mapa cieplna strony głównej 


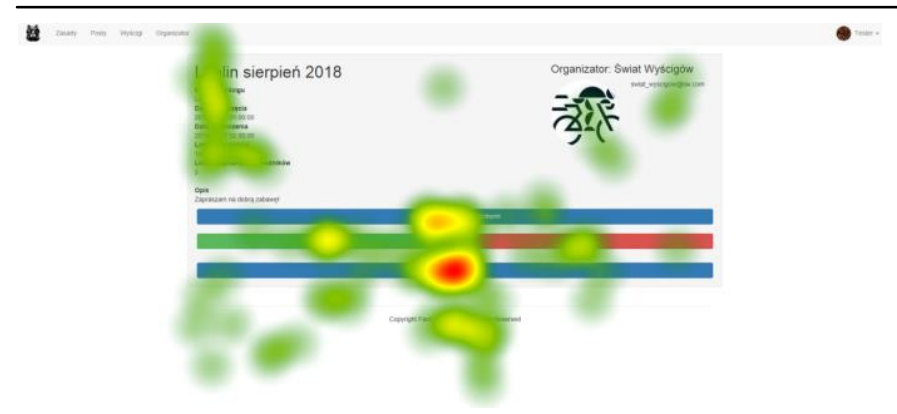

Rys. 3. Mapa cieplna dla zadania 2 (zapisywanie się na wyścig)

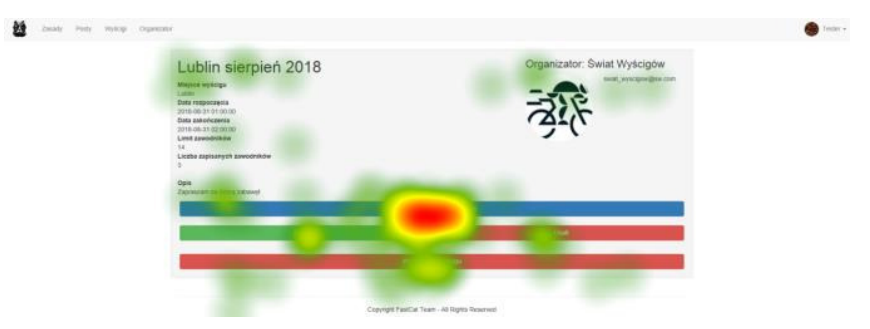

Rys. 4. Mapa cieplna dla zadania 4 (tworzenie punktu kontrolnego)

\section{Analiza i dyskusja rezultatów eksperymentu}

Analiza czasów wykonania poszczególnych zadań (tab. 1) wskazuje na znaczne zróżnicowanie szybkości realizacji działań w interfejsie. Różnica w łącznym czasie wykonania zadań była ponad 8. krotna, jak 166 sek. do 1430 sek.(tab. 1). Taka różnica może świadczyć o niedostosowaniu interfejsu do pewnej, niedoświadczonej grupy użytkowników.

Duże wartości średnich i maksymalnych czasów realizacji (tab. 1) dość prostych zadań (zadania numer 1 i 3) sygnalizują problemy z użytecznością podstron, realizujących te zadania. Potwierdza to analiza błędów wykrytych przez użytkowników na tych podstronach - tab. 4. Głównie były to problemy $\mathrm{z}$ odnalezieniem funkcjonalności na ekranie (oznaczenie $\mathrm{X}$ w tab. 4). Proste zadanie (numer 5, tj. usunięcie własnego postu) sprawiało również problem (tab. 4), a i czasy jego realizacji były stosunkowo duże (tab. 3 ).

Segmentacja ekranu pozwoliła ustalić przyczynę części błędów i zwiększonego czasu realizacji zadań. Była nią umieszczenie menu w prawej górnej części ekranu, na które to użytkownicy rzadko koncentrowali uwagę - tab. 2. Potwierdzają to mapy cieplne wykonania zadania numer 1 rys. 2. Wyraźnie $z$ niej można odczytać (rys. 2), że użytkownicy poszukiwali opcji „nowy post” w lewej górnej części ekranu. Zjawisko błędnego poszukiwania wystąpiło w zadaniu 2 i następnych, w których, nauczeni w trakcie realizacji poprzedniego zadania, użytkownicy poszukiwali opcji zapisywania na wyścig w różnych miejscach ekranu, rzadziej zwracając na lewy górny róg gdzie ta opcja była umieszczona - rys. 3 i 4 . Wskazuje to na dość chaotyczną strukturę interfejs.

Największa liczba błędów została popełniona podczas realizacji zadania 1 (tab. 4). Błędem podczas wykonania tego zadania było m.in. wejście na złą podstronę $(\mathrm{X})$, niepoprawne wypełnienie danego formularza $(\mathrm{Y})$ oraz mylne przekonanie o ukończeniu zadania (Z), np. usunięcie wyścigu przy zadaniu polegającym na usunięciu postu. Sporą część popełnionych błędów stanowiło przejście na złą podstronę (X w tab. 4).

$\mathrm{Na}$ 92. popełnionych wszystkich błędów tylko 7. razy uczestnicy musieli ponownie wypełniać formularz. Zadania 2 oraz 4 przysporzyły najmniej problemów. Podczas ich wykonywania popełniono tylko jeden błąd. Błędy z zadania 3 wynikają z negatywnego przyswojenia/nauczenia się interfejsu strony - badani użytkownicy szukali formularza w tym samym miejscu, gdzie ostatecznie znaleźli formularz dotyczący zadania 1. Warto zwrócić uwagę na uczestnika numer 2, który mimo tego, iż najdłużej wykonywał zadania nie popełnił największej liczby błędów. Uczestnik 4 popełnił w sumie 27 błędów, uczestnik 2, tylko 21. Uczestnik 3 wykonał o 2 błędy mniej, z czasem prawie 3 razy mniejszym. Liczba popełnionych błędów ma wpływ na czas wykonania zadania. Można wywnioskować także w stosunku do użytkownika numer 2, że anomalia w czasie realizacji zadań wynika raczej ze stresu, jaki odczuwał ten uczestnik podczas realizacji eksperymentu.

\section{Wnioski}

Wyniki badań interfejsu aplikacji internetowej przy wykorzystaniu eye-trackingu wskazały na istnienie znaczącego problemu $\mathrm{z}$ brakiem ujednolicenia interfejsu aplikacji webowej systemu FastCat. Metoda ta umożliwiła zbadanie użyteczności danego interfejsu, z wykorzystaniem eksperymentu z udziałem użytkowników. Błędy, które zostały wykryte, miały znaczny wpływ na komfort korzystania (i jakość interfejsu) $\mathrm{z}$ aplikacji przez uczestników eksperymentu.

Podstawowym wnioskiem ze zrealizowanych badań, jest konieczność przeprojektowania interfejsu pod kątem ujednolicenia nawigacji w nim oraz usunięcia problemów $\mathrm{z}$ wypełnieniem formularzy ( $w$ tym, i usunięcie konieczności ponownego wprowadzania danych do formularza po wystąpieniu błędnego działania użytkownika).

Opracowana w LARiEI metodyka badań interfejsów w warunkach quasi-realnych [8] sprawdziła się w praktyce, co potwierdza duża liczba znalezionych problemów z interfejsem bardzo prostej aplikacji webowej przy stosunkowo niewielkiej próbie badawczej.

\section{Literatura}

[1] H. Bozikovic, M. Stula, Web design - Past, present and future, 41st International Convention on Information and Communication Technology, Electronics and Microelectronics, MIPRO 2018. Proceedings, 2018, pp. 1476-1481.

[2] J. Bernacki, I. Błażejczyk, A. Indyka-Piasecka, M. Kopel, E. Kukla, B. Trawiński, Responsive Web Design: Testing Usability of Mobile Web Applications, Lecture Notes in Computer Science, vol. 9621, 2016, pp. 257-269.

[3] J. Nielsen, T. Landauer, A mathematical model of the finding of usability problems, Proceedings of ACM INTERCHI'93 Conference, April 1993, pp. 206-213

[4] M. Miłosz, Ergonomia systemów informatycznych, Poliechnika Lubelska, 2014, $126 \mathrm{~s}$. 
[5] J. Karn, Eye tracking in human-computer interaction and usability research: Ready to deliver the promises, The Mind's Eye: Cognitive and Applied Aspect of Eye Movement Research. Hyona, Radach \& Deubel (eds.) Oxford, England, 2003, 574-576.

[6] P. Chynal, J.M. Szymanski, J. Sobecki, Using Eyetracking in a Mobile Applications Usability Testing, Lecture Notes in Computer Science, vol. 7198, 2012, pp. 178-186.

[7] M. Jusiak, J. Wrzos, B. Milaniuk, M. Garbala, System wspomagający obsługę miejskich wyścigów rowerowych, Praca dyplomowa, Politechnika Lubelska, Lublin, 2017, 94 str.

[8] M. Borys, M. Miłosz, Mobile application usability testing in quasi-real conditions a case study of a mobile eye tracker, 8th International Conference on Human System Interactions, IEEE, 2015, pp. 381-387. 